\title{
A rare complication: right contralateral hemopneumothorax after pacemaker implantation
}

\author{
Victor S. Alemany ${ }^{1, A-F}$, Abdalla Sherif Hassan Attia ${ }^{2, A-D, F}$ \\ A - Research concept and design, B - Collection and/or assembly of data, C - Data analysis and interpretation, \\ D - Writing the article, E - Critical revision of the article, F - Final approval of article \\ 1. Physician Affiliate Group of New York Health and Research Foundation \\ 2. Ain Shams University
}

Address for correspondence:

Victor S. Alemany, Physician Affiliate Group of New York Health and Research Foundation email: salemanyv@gmail.com

Abdalla Sherif Hassan Attia, Ain Shams University

email: abdallasherif0100524@med.edu.eg

Received: 2019-01-29

Revised:

Accepted: 2019-02-02

Final review:

DOI: $10.24255 / \mathrm{hbj} / 103615$

\section{Key words:}

hemopneumothorax, catheterism, arrhythmia, pacemaker-related complication, pacemaker implantation

\section{Abstract}

\section{Background}

Pneumothorax as an early complication of pacemaker implantation occurs with a frequency between $0.9 \%$ and $1.9 \%$. However, the usual presentation of pneumothorax is ipsilateral to the subclavian vein where the catheter is being inserted.

\section{Material and methods}

Here we present an uncommon case of contralateral pneumothorax after pacemaker implantation through catheterization of the left subclavian vein.

\section{Results}

An 87-year-old male patient who underwent permanent pacemaker implantation four days previously came to the emergency room with right pleuritic chest pain and associated dyspnea for four days, stating that the symptoms began after the pacemaker implantation.

On admission the physical examination was normal, hemodynamically stable, afebrile, and basal oxygen saturation was $99 \%$, without cardiopulmonary auscultation findings. The electrocardiogram showed sinus rhythm at $50 \mathrm{bpm}$

without alterations and chest radiography suggested right pleural effusion.

Chest X-ray performed after the pacemaker implantation (left subclavian access) revealed a right pneumothorax. Assessment was completed with chest computed tomography (CT), showing a right hemopneumothorax. Anterior drainage was decided after the patient was admitted to the Thoracic Surgery Service.

A diagnosis of iatrogenic right pneumothorax after pacemaker implantation was made.

The Arrhythmia Unit considered the release of one of the active fixation systems during the procedure as the most probable cause of the hemopneumothorax. There was no perforation in the auricular cable's current location.

\section{Conclusion}

This exceptional case shows that doctors should be aware of infrequent complications related to ordinary procedures and keep in mind the signs and symptoms to make the differential diagnosis. 
Pacemaker implantation is a standard procedure that has been performed in the US for over 58 years now. 1 The frequency of complications related to pacemaker implantation is variable, between $6 \%$ and $9 \%$, and there are different factors related to them. The most frequent are an inexperienced operator and the occurrence of heart failure prior to implantation.

Pneumothorax as an early complication of pacemaker implantation occurs with a frequency between $0.9 \%$ and $1.9 \% .2,9$ The typical presentation of pneumothorax is ipsilateral to the subclavian vein where the catheter is being inserted. There are very few cases where pneumothorax contralateral to the catheter insertion side has been reported.3,4,5,6

The risk factors for pneumothorax due to catheterization are COPD, DM, CKD, steroid usage, only warfarin as anticoagulant usage 7 and patients over 70 years old 8 . The outcome after a pneumothorax is generally positive after treatment.

Here we present an uncommon case of contralateral pneumothorax after pacemaker implantation through catheterization of the left subclavian vein.

\section{Case}

The case concerns an 87-year-old male patient with known cardiovascular risk factors, a history of cardiac arrest treated with right coronary stent implantation and a permanent pacemaker for symptomatic atrial dysfunction through catheterization of the left subclavian vein.

The patient came to the emergency room with right pleuritic chest pain and associated dyspnea for four days, stating that the symptoms began after the pacemaker implantation.

On admission the physical examination was normal, hemodynamically stable, afebrile, and basal oxygen saturation was $99 \%$, without cardiopulmonary auscultation findings or in the rest of the examination. Blood tests were without alterations, NT-pro-BNP: 411, raised D-dimer, electrocardiogram with sinus rhythm at $50 \mathrm{bpm}$ without alterations and chest radiograph suggestive of right pleural effusion.

Chest X-ray performed after the pacemaker implantation (left subclavian access) revealed a right pneumothorax.

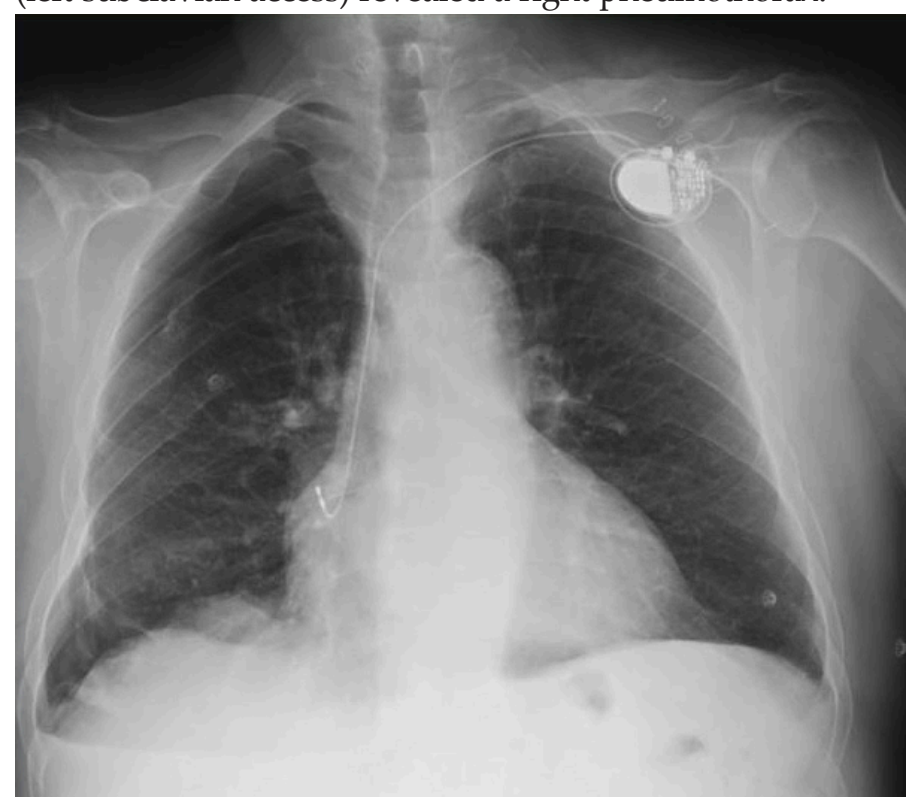

Assessment was completed with chest computed tomography $(\mathrm{CT})$, showing a right hemopneumothorax.
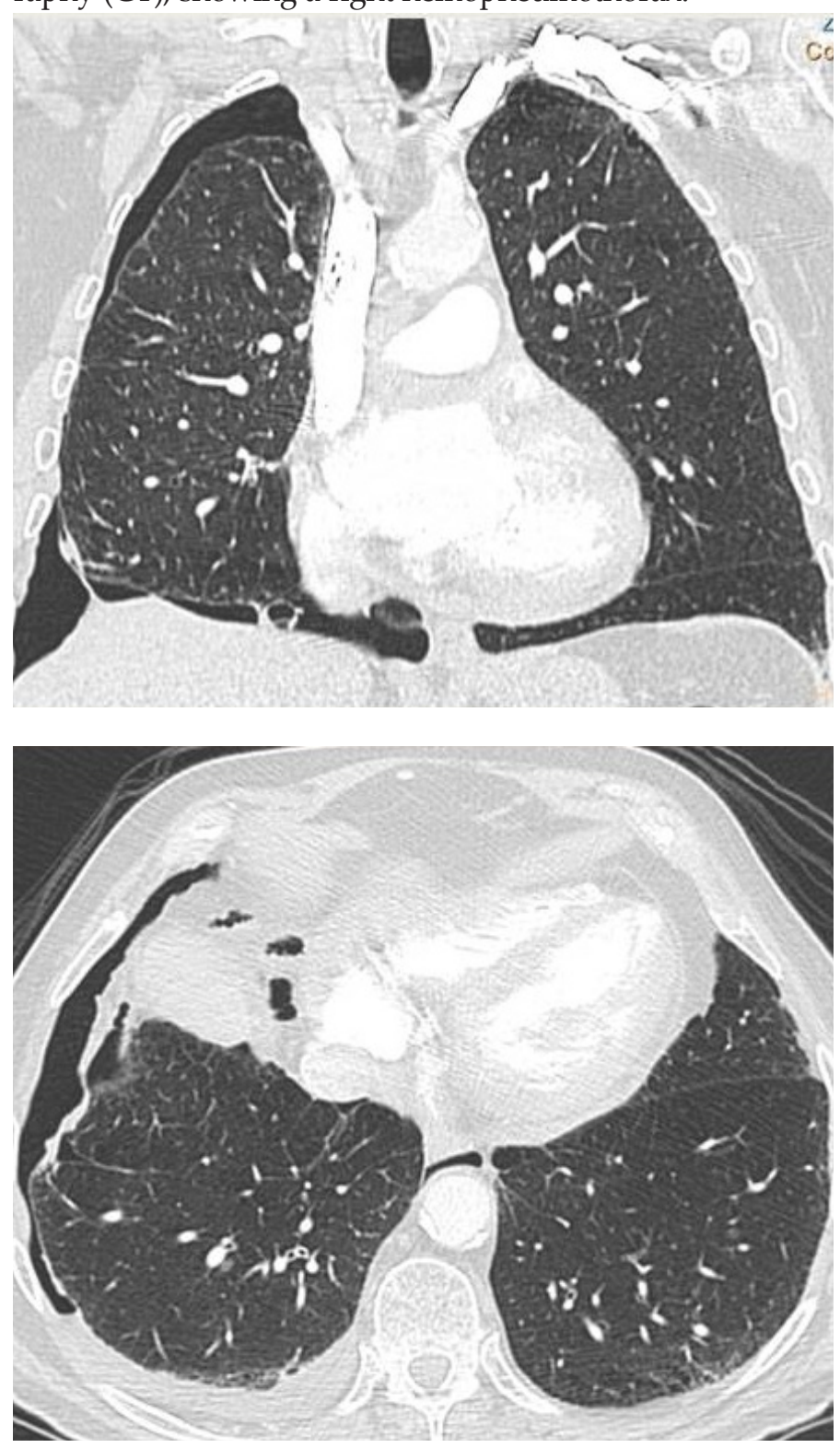

Thoracic surgeons were consulted during hospitalization and decided to place an anterior drainage after the patient was admitted to the Thoracic Surgery Service.

A diagnosis of iatrogenic right pneumothorax after pacemaker implantation was made.

The patient was admitted with favorable evolution. He was valued by the Arrhythmia Unit during the income. They considered the release of one of the active fixation systems during the procedure as the most probable cause of the hemopneumothorax. There was no perforation in the auricular cable's current location.

This exceptional case shows that doctors should be aware of infrequent complications related to ordinary procedures and keep in mind the signs and symptoms to make the differential diagnosis. 


\section{References}

1. 50th anniversary of the first successful permanent pacemaker implantation in the United States: Historical review and future directions. Beck H., Boden W.E., Patibandla S., Kireyev D., Gupta V., Campagna F., Cain M.E., Marine J.E. (2010) American Journal of Cardiology, 106 (6), pp. 810-818.

2. Are elderly patients at increased risk of complications following pacemaker implantation? A meta-analysis of randomized trials.

3. Dilling-Boer D, Ector H, Willems R, Heidbuchel H. Pericardial effusion and right-sided pneumothorax resulting from an atrial active-fixation lead. Europace. 2003;5:419-23

4. Van Herendael H, Willems R. Contralateral pneumothorax after endocardial dual-chamber pacemaker implantation resulting from atrial lead perforation. Acta Cardiol. 2009;64:271-3.

5. Srivathsan K, Byrne RA, Appleton CP, Scott LR. Pneumopericardium and pneumothorax contralateral to venous access site after permanent pacemaker implantation.

6. Pettemerides V, Jenkins N. Contralateral pneumothorax following repositioning of an atrial lead. Europace. 2012;14:606

7. Lin YS, Hung SP, Chen PR, et al. Risk factors influencing complications of cardiac implantable electronic device implantation: infection, pneumothorax and heart perforation: a nationwide population-based cohort study. Medicine (Baltimore). 2014;93(27):e213.

8. Ozcan KS, Osmonov D, Altay S, et al. Pacemaker implantation complication rates in elderly and young patients. Clin Interv Aging. 2013;8:1051-4

9. Incidence, predictors, and outcomes associated with pneumothorax during cardiac electronic device implantation: A 16-year review in over 3.7 million patients. Ogunbayo, Gbolahan O. et al. heart Rhythm , Volume 14, Issue 12, 1764 - 1770 